\title{
Cut-Edge Corrosion Behavior of Prepainted 55\% AI-Zn Steel with Chromate-free Primers in Various Atmospheric Environments
}

\author{
Takahiro TSUJITA, ${ }^{1) *}$ Azusa OOI, ${ }^{2)}$ Eiji TADA $^{21}$ and Atsushi NISHIKATA ${ }^{2)}$ \\ 1) AkzoNobel Coatings KK, 296 Shimokurata-cho, Totsuka-ku, Yokohama, Kanagawa, 244-0815 Japan. \\ 2) School of Materials and Chemical Technology, Tokyo Institute of Technology, 2-12-1 Ookayama, Meguro-ku, Tokyo, 152- \\ 8550 Japan.
}

(Received on April 12, 2021; accepted on June 1, 2021)

\begin{abstract}
Outdoor exposure tests of prepainted 55\% Al-Zn steel sheets are performed for 24 months at five different exposure sites: Tokyo, Kagoshima, and Okinawa in Japan, and Arizona and Florida in the United States. The anticorrosive pigments in the primer with topcoat are strontium chromate ( $\mathrm{Cr})$, magnesium vanadate + zinc phosphate (MgV/ZnP), calcium silicate (Si), and magnesium vanadate (MgV). The edge creep is evaluated by measuring the creep width every six months. The electrochemical impedance and polarization curves of the non-coated $55 \% \mathrm{Al}-\mathrm{Zn}$ steel and carbon steel (CS) are measured in a $3 \% \mathrm{NaCl}$ solution suspended with the anticorrosive pigments. The corrosion products at the cut edge are analyzed by scanning electron microscopy and energy dispersive X-ray spectrometry.

The edge creep for all the specimens did not progress at all in Arizona (dry desert), although red rust appears on the CS surface at the cut edge. At Kagoshima and Okinawa (marine atmospheres), the progress of the edge creep is fast for all the specimens. It is especially significant in Okinawa where temperature and humidity are high. When comparing the effects of the pigments on the edge creep properties, the results show that $\mathrm{Si}$ is poor at all exposure sites except Arizona, and MgV/ZnP shows edge creep properties comparable to $\mathrm{Cr}$. From the anodic polarization characteristics of $55 \% \mathrm{Al}-\mathrm{Zn}$ steel and the cathodic polarization curve of CS, the effect of the pigments on edge creep is successfully described.
\end{abstract}

KEY WORDS: prepainted steel; 55\% Al-Zn; edge creep; corrosion; anticorrosive pigments; chromate-free; electrochemical impedance spectroscopy.

\section{Introduction}

Prepainted steel sheets for exterior building materials are made for roofing and siding projects; $55 \% \mathrm{Al}-\mathrm{Zn}$ steel ${ }^{1,2)}$ is painted on both sides with a chemical conversion treatment. Generally, specifications for the front side include a double coat of primer and topcoat with a total dry film thickness of approximately $20 \mu \mathrm{m}$. The general specification for the backside is a single or double coat of primer and back coat with a total dry film thickness of 5-7 $\mu \mathrm{m}$. Prepainted steel sheets for exterior building materials are required to have long-term corrosion and weather resistance in the painted flat areas, molded parts, and in the cut edge where the metal parts are exposed. A common anticorrosive pigment is hexavalent chromium.

Recently, to reduce environmentally hazardous substances, it is required to establish technology for chemical conversion and chromate-free primers that do not contain hexavalent chromium. Prepainted steel sheets used for

\footnotetext{
*Corresponding author: E-mail: takahiro.tsujita@akzonobel.com
}

home appliances already utilize chromate-free primers. ${ }^{3,4)}$ However, for building materials, it will take a long time to establish chromate-free technology $y^{5,6)}$ as evaluation of long-term durability and corrosion resistance are required.

In Europe, the use of environmentally hazardous substances such as hexavalent chromium is controlled and regulated through the Restriction of Hazardous Substances and the Registration Evaluation Authorization and Restriction of Chemicals (REACH). Therefore, in many European countries, the use of chromate-free materials for building materials is progressing. $\mathrm{REACH}$ has designated chromate pigments that are used as anticorrosive pigments for primers as controlled substances, and in the European Union region restrictions have been in place since January 2019. ${ }^{7}$ In Japan, the standard specifications for public building construction (Ministry of Land, Infrastructure, Transport and Tourism) were revised in 2013, and paint containing lead and chromium was completely eliminated for after-coated steel sheets (on-site painting). Additionally, chromate-free specifications were standardized in the Japanese Industrial Standards for prepainted steel sheets in 2013. ${ }^{8 \text { ) }}$ 
The anticorrosion performance of chromate-free coating systems was evaluated by comparing it with conventional chromate systems in outdoor exposure tests. Comparative evaluation results of the degradation of painted $55 \% \mathrm{Al}-\mathrm{Zn}$ steel and galvanized steel sheets at exposure sites located at Okinawa, Akita, and Niigata were available. ${ }^{9)}$ Proskek et al. studied one effect of climatic parameters on the cut edge corrosion of painted $\mathrm{Zn}-\mathrm{Mg}$ and $\mathrm{Zn}-\mathrm{Al}-\mathrm{Mg}$ alloy steel. ${ }^{10)}$ Ueda et al. studied the corrosion mechanism of the cut edge from the results of an exposure test at Okinawa for $\mathrm{Zn}-11 \%$ $\mathrm{Al}-3 \% \mathrm{Mg}-0.2 \% \mathrm{Si}$ alloy steel. ${ }^{11)}$ Shinohara reported on the corrosion-protection mechanism of zinc-coated steel sheets compared with carbon steel (CS) sheets in a natural exposure test. ${ }^{12)}$ Sugawara et al. compared the role of magnesium phosphate and strontium chromate pigments in accelerated tests on the corrosion resistance of $55 \% \mathrm{Al}-\mathrm{Zn}$ steel. ${ }^{13)}$ Townsend reported on the corrosion resistance of galvanized steel sheets and 55\% Al-Zn steel with natural exposure tests in different environments. ${ }^{14)}$ Nomura et al. reported on an example of the corrosion resistance of $55 \% \mathrm{Al}-2 \% \mathrm{Mg}-\mathrm{Zn}$ alloy steel sheets compared with 55\% $\mathrm{Al}-\mathrm{Zn}$ steel. ${ }^{15)}$ However, there are only a few reports of systematic exposure tests of chromate-free prepainted steel sheets in different climatic environments. Accelerated tests such as the salt spray test $(\mathrm{SST})^{16)}$ and the cyclic corrosion test $(\mathrm{CCT})^{17)}$ are also applied to evaluate the chromate-free prepainted steel sheets. Kajiyama et al. studied new accelerated corrosion test methods by alternating SST and CCT. ${ }^{18)}$ Matsuda et al. studied the relationship between accelerated test results and 44-month outdoor exposure test results. ${ }^{19)}$ However, in general, test results did not always highly correlate with natural environment long-term exposure tests.

Electrochemical methods $\mathrm{s}^{20,21)}$ were applied to evaluate the corrosion behavior after exposure tests and accelerated tests. ${ }^{10,22,23)}$ Regarding the cut edge corrosion, Nishikata et al. proposed a method for measuring the local electrochemical impedance spectroscopy (EIS) near the cut edge that appeared intact to the naked eye and evaluated the degree of the degradation of the paint via EIS. ${ }^{22)}$ Research results of $\mathrm{Zn}$ and $55 \% \mathrm{Al}-\mathrm{Zn}$ steel sheets as well as the role of chromate pigments were discussed. This paper discussed the effects of the differences in the anticorrosive pigments contained in the primer on $55 \% \mathrm{Al}-\mathrm{Zn}$ steel sheets based on the results of exposure tests in Japan and in the United States.

\section{Experimental}

\subsection{Precoated Steel Sheets}

This study used 55\% Al-Zn steel sheets (GL, alloy metal weight $150 \mathrm{~g} / \mathrm{m}^{2}$ ) with a substrate thickness of $0.4 \mathrm{~mm}$. On the surface, the primer and topcoat were applied with a 2-coat-2-bake process. Figure 1 shows the structure of the prepainted steel sheet. Four different precoated steel sheets were used in each exposure test. Table 1 describes the details of the precoatings. Each sheet had a different pigment in the primer; strontium chromate $(\mathrm{Cr})$, a mixture of magnesium vanadate and zinc phosphate $(\mathrm{MgV} / \mathrm{ZnP})$, calcium ion-exchange silica $(\mathrm{Si})$, and magnesium vanadate $(\mathrm{MgV})$. The topcoats were conventional polyester/melamine paint or polyester/urethane paint. The backside of all the test pieces was painted with an epoxy primer of $\mathrm{MgV} / \mathrm{ZnP}$ (5

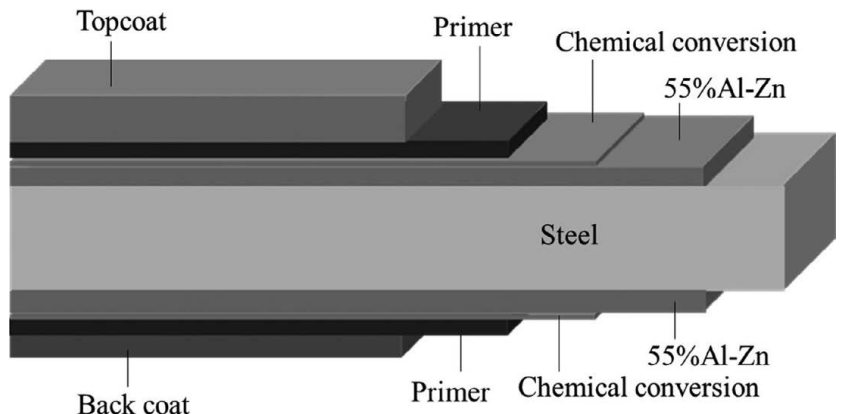

Fig. 1. Schematic drawing of coating layers of pre-coated steel sheet.

Table 1. Coating specifications.

\begin{tabular}{ccccccc}
\hline \multirow{2}{*}{ Name } & \multicolumn{3}{c}{ Primer } & & & \multicolumn{2}{c}{ Topcoat } \\
\cline { 2 - 4 } \cline { 5 - 6 } & Binder & $\mathrm{ACP}^{*}$ & $\mathrm{DFT}^{*} / \mu \mathrm{m}$ & & Binder & $\mathrm{DFT}^{*} / \mu \mathrm{m}$ \\
\hline $\mathrm{CR}$ & Epoxy & $\mathrm{Cr}$ & 5 & & Polyester & 15 \\
$\mathrm{CF}-1$ & Epoxy & $\mathrm{MgV} / \mathrm{ZnP}$ & 5 & & Polyurethane & 15 \\
$\mathrm{CF}-2$ & Polyurethane & $\mathrm{Si}$ & 25 & & Polyurethane & 15 \\
$\mathrm{CF}-3$ & Polyurethane & $\mathrm{MgV}$ & 25 & & Polyurethane & 15 \\
\hline
\end{tabular}

*ACP: Anti corrosive pigment, DFT: Dry film thickness

$\mu \mathrm{m}$ thick) and an epoxy topcoat (6 $\mu \mathrm{m}$ thick).

\subsection{Outdoor Exposure Tests}

The exposure tests were performed at five different sites: (1) Shinjuku, Tokyo, Japan; (2) Kirishima, Kagoshima, Japan; (3) Miyakojima, Okinawa, Japan; (4) South Florida, USA; (5) Arizona, USA. The exposure period was 24 months. Tokyo (TYO) is classified as an urban area in a temperate zone (19 km from the coast). Kagoshima (KAG) is a volcanic area in a temperate zone ( $2 \mathrm{~km}$ from the coast). Okinawa $(\mathrm{OK})$ is a marine area in a subtropical zone $(2 \mathrm{~km}$ from the coast). South Florida (FL) is in a subtropical zone (19 $\mathrm{km}$ from the coast), and Arizona (AZ) is a desert area in a dry zone (200 km from the coast). Table 2 shows the average outside temperature, the average relative humidity, and the radiation-exposure levels monitored at the exposure sites. The average temperature was higher at the exposure sites of $\mathrm{OK}, \mathrm{FL}$, and AZ. The average humidity was higher at $\mathrm{KAG}, \mathrm{OK}$, and FL, and was extremely low in AZ. It was expected that KAG and OK would have the largest amount of airborne sea salt due to their low distance from the coast. Therefore, it was predicted from these climate conditions that $\mathrm{OK}$ would be the most aggressive, KAG and FL would be moderate, TYO would be relatively mild, and AZ would be the least corrosive.

The test pieces were cut from the painted steel plates in Table 1 to $150 \times 35 \mathrm{~mm}$ with a shear cutter so that the burrs were on one edge and the other edge faced up and down, respectively. The schematic drawing of this is shown in Fig. 2. Four cuts of each test piece were exposed at each site, and one was removed every 6 months to measure the edge creep width. The creep widths (both at the upward and downward burrs) were randomly selected and measured at 10 points, $100 \mathrm{~mm}$ in length, along the cut edges. The progress of the cut edge corrosion was evaluated via the average value. 
Table 2. Weathering data measured at the exposure sites.

\begin{tabular}{cccccc}
\hline Location & $\begin{array}{c}\text { Tokyo (TYO) } \\
\text { Shinjuku }\end{array}$ & $\begin{array}{c}\text { Kagoshima (KAG) } \\
\text { Kirishima }\end{array}$ & $\begin{array}{c}\text { Okinawa (OK) } \\
\text { Miyako }\end{array}$ & $\begin{array}{c}\text { America (FL) } \\
\text { S. Florida }\end{array}$ & $\begin{array}{c}\text { America (AZ) } \\
\text { Arizona }\end{array}$ \\
\hline Classification & Temparate Urban & Temparate Marine, Volcano & Subtropical Marine & Subtropical & Desert \\
\hline Distance from coast $(\mathrm{km})$ & 19 & 2 & 2 & 19 & 200 \\
Exposure angle (degree) & 45 & 30 & 20 & 25 & 45 \\
Average temperature $\left({ }^{\circ} \mathrm{C}\right)$ & 15.1 & 16.2 & 23.8 & 24.6 & 21.4 \\
Average humidity $(\% \mathrm{RH})$ & 61.5 & 88.9 & 79.4 & 75.8 & 35.9 \\
Radiant exposure $\left(\mathrm{MJ}^{-2}\right)$ & 21.5 & 27.8 & 29.4 & 24.8 & 25.4 \\
\hline
\end{tabular}

(b)

(a)
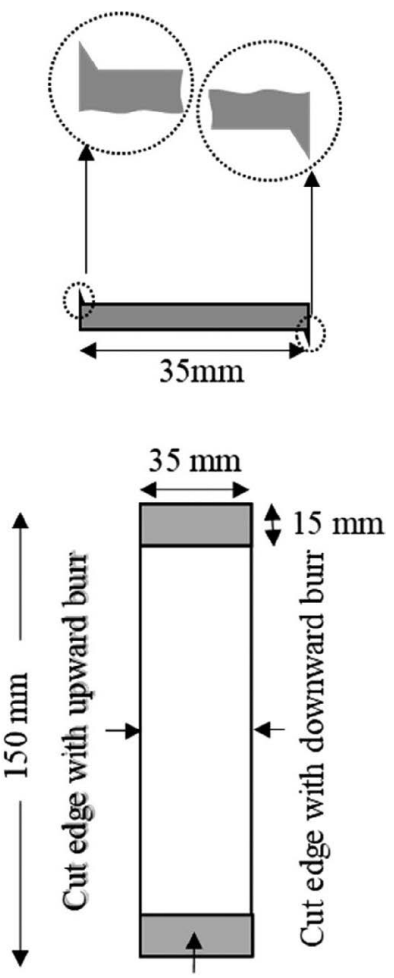

Area for fixing to rack

Fig. 2. Specimen for exposure test.

\subsection{Cross-section Analysis of the Cut Edge}

The cross-section of the cut edge, after 24 months of exposure, was observed and analyzed with a scanning electron microscope (SEM, S-3400N, Hitachi) and energy dispersive X-ray spectrometry (EDS).

\subsection{Electrochemical Tests}

As shown in Fig. 3, the anticorrosion ability of the pigment for the 55\% Al-Zn coating and carbon steel (CS) substrate was evaluated via electrochemical methods using a three-electrode cell. A silicone ring with an inner diameter of $8 \mathrm{~mm}$ was placed on the working electrode surface of the $55 \% \mathrm{Al}-\mathrm{Zn}$ steel sheet or CS sheet, and an acrylic tube with an inner diameter of $32 \mathrm{~mm}$ with an acrylic flange was fixed vertically on it. A $3 \% \mathrm{NaCl}$ solution suspended with the pigments was poured into the acrylic tube as the test solution. A silver/silver chloride electrode $(\mathrm{Ag} / \mathrm{AgCl}$, sat. $\mathrm{KCl}, \mathrm{SSE}$ ) and a platinum electrode were used as the reference electrode and counter electrode, respectively. After the open circuit potential (OCP) was stabilized (approximately $30 \mathrm{~min}$.), the EIS was first measured using an electrochemi-

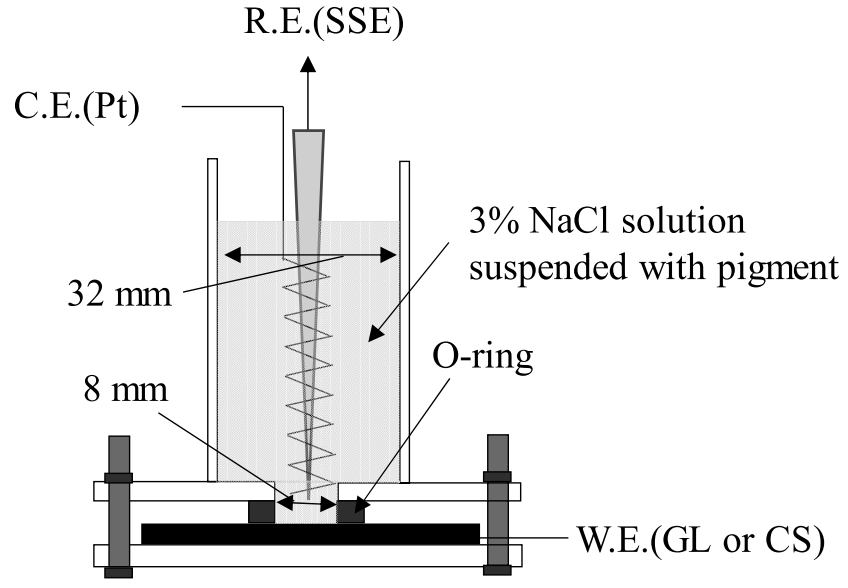

Fig. 3. Schematic diagram of electrochemical cell.

cal measurement unit (IVUIM STAT). Next, the anodic polarization curve was measured at $1 \mathrm{mV} \cdot \mathrm{s}^{-1}$ from $E_{\text {corr }}$ in a positive direction. Similarly, the cathodic polarization curve was measured from $E_{\text {corr }}$ using a fresh working electrode. The EIS was measured at the OCP with a $10 \mathrm{mV}$ amplitude and in the frequency range of $100 \mathrm{kHz}-10 \mathrm{mHz}$.

\section{Results}

\subsection{Outdoor Exposure Test}

3.1.1. Edge Creep

Figure 4 shows the changes in the edge creep width (ECW) with time for each exposure site. The ECW values obtained at the upper and lower burrs of the cut edges were not largely different. Therefore, the average value is plotted in the figure. The progress of the edge creep stopped within 24 months in some cases and not in others. For example, at $\mathrm{OK}$, the ECW of CF-1 increased to about $0.5 \mathrm{~mm}$ in the first 12 months and then stayed constant. The ECW of CF-2 became constant at $2.5 \mathrm{~mm}$ after 18 months. Conversely, CR and CF-3 continued to progress even after 24 months. Although the edge creep may still progress after 24 months of exposure, the differences in the cut edge corrosion characteristics using the 24-month ECW values are discussed in this article.

When comparing the ECW at the exposure sites, it increased in the order of $\mathrm{AZ}<\mathrm{TYO}<\mathrm{FL}<\mathrm{KAG}<\mathrm{OK}$. The order can be predicted from the differences in the environmental factors shown in Table 2.

The edge creep did not progress at all for all of the specimens exposed in AZ, even after two years of exposure, 

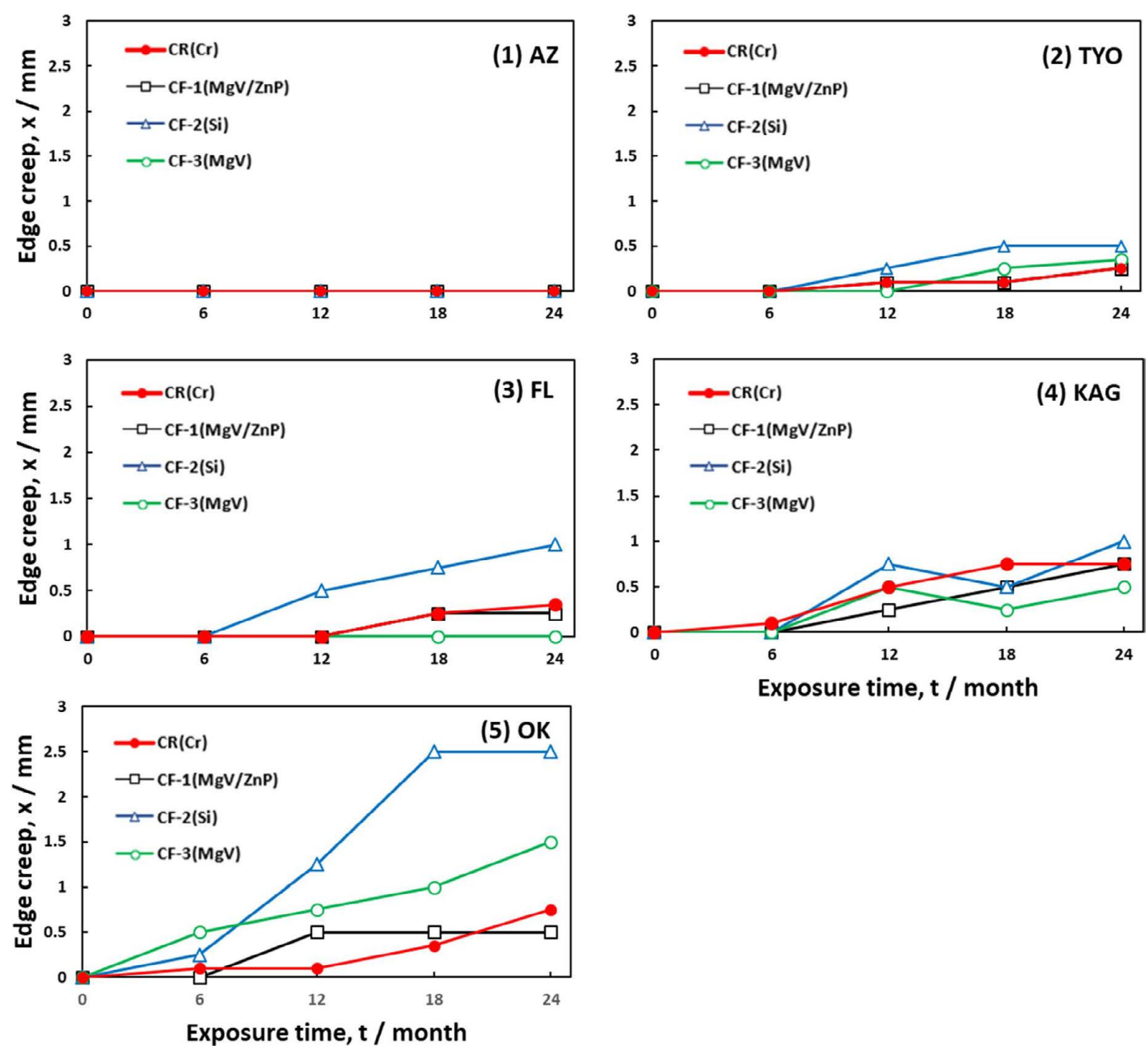

Fig. 4. Plots of average edge creep width with exposure time at (1) Arizona (AZ), (2) Tokyo (TYO), (3) Florida (FL), (4) Kagoshima (KAG) and (5) Okinawa (OK). (Online version in color.)

although red rust was observed at the cut edge. This result indicates that the sacrificial protection by the $55 \% \mathrm{Al}-\mathrm{Zn}$ coating did not work in AZ where the average relative humidity is $35.9 \%$ (a dry zone). At the other sites, no visible red rust was observed at the cut edges of the specimens. In TYO and FL, the edge creep for all the specimens (except CF-2) barely progressed at 12 months of exposure. It then slightly progressed to $\sim 0.25 \mathrm{~mm}$ at 24 months. At KAG, a volcanic and marine environment, the ECW of all the specimens began to increase after six months of exposure. These results indicate that KAG is a more aggressive environment than TYO and FL are. At OK, the highest exposure site in average temperature, humidity, and airborne sea salt, the edge creep of all the specimens progressed significantly (especially that of CF-2), reaching $2.5 \mathrm{~mm}$ at 18 months. When comparing the edge creep resistance of all the specimens, it is clear that CF-2 is the worst at all exposure sites (except AZ, where the edge creep of all the specimens did not progress). The difference in the creep resistance among CF-1, CF-3, and CR is slightly complicated. At TYO, there was no significant difference in ECW except for CF-2. In FL and KAG, CF-3 showed better creep resistance than CF-1 and CR. In particular, the edge creep of CF-3 did not progress for 24 months in FL. On the other hand, at $\mathrm{OK}$, the edge creep of CF-3 progressed at a considerably higher rate than that of CF-1 and CR. CF-3 showed excellent creep resistance at the moderately corrosive sites in FL and KAG, but it may not have been sufficient at the most corrosive site in OK. Finally, when comparing the performance of CF-1 with CR, CF-1 showed edge creep resistance equivalent to $\mathrm{CR}$ at all exposed sites. The ECW value of CF-1 at 24 months was almost the same as CR at KAG whereas CR reached an almost constant value after 18 months of exposure. However, CF-1 was still progressing even after 24 months. In contrast, at $\mathrm{OK}$, the ECW of CF-1 at 24 months was slightly smaller than that of CR. The ECW of CF-1 converges to a constant value at 12 months, whereas the edge creep of CR hardly progressed until 12 months, when it started to progress (and it may continue to progress even after 24 months).

In summary, the $\mathrm{MgV} / \mathrm{ZnP}$ pigment ( $\mathrm{CF}-1)$ had equivalent cut-edge corrosion resistance to the $\mathrm{Cr}$ pigment (CR) at all exposure sites. The Si pigment (CF-2) had the worst corrosion resistance at the cut edge. The $\mathrm{MgV}$ pigment $(\mathrm{CF}-$ 3) was poorly corrosion resistant in high temperature, high humidity, and high airborne sea salt environments such as OK, but was highly corrosion resistant in a moderate environment like FL and/or KAG.

\subsubsection{Cross-section Observation}

The cross-sections near the cut edge of the upward burr side on the specimens exposed in $\mathrm{OK}$ for two years were 
observed. Figure 5 shows the SEM images of the crosssections of the cut edge of (1) CR (Cr), (2) CF-1 (MgV/ $\mathrm{ZnP}$ ), (3) CF-2 (Si), and (4) CF-3 (MgV). This photo is a cross-sectional view of approximately $400 \mu \mathrm{m}$ from the tip of the cut edge. Since the actual edge creep width was approximately $500 \mu \mathrm{m}$ for CR and CF-1, $2500 \mu \mathrm{m}$ for CF-2 and $1500 \mu \mathrm{m}$ for CF-3 (Fig. 4), the photos of CR and CF-1 are of almost whole peeled parts, and the photos of CF-2 and CF-3 are only of the tip of the peeled parts. The amount of corrosion products under the coating film was relatively small for CR and CF-1 and large for CF-2 and CF-3. Additionally, the corrosion products are observed in the area slightly away from the tip in CF-2, but in the part near the tip in CF-3. In all cases, the plating layer remained intact up to the tip of the cut edge. Only the Zn-rich layer preferentially dissolved and the Al-rich layer remained. The exposed steel surface of the cut edge was completely covered with the corrosion products of the $\mathrm{Zn}-\mathrm{Al}$ coating. Among all the test specimens, CR had the thickest corrosion product layer (approximately $20 \mu \mathrm{m}$ ) on the cut edge surface.

Table 3 shows the EDS point analysis results of the corrosion products of $\mathrm{CR}(\mathrm{Cr})$ and $\mathrm{CF}-1$ ( MgV/ZnP). The point analysis was performed on the steel surface of the cut edge [Point (A)] and under the paint [Point (B)]. In all cases, $\mathrm{Al}$ and $\mathrm{Zn}$ were detected. A mixture of $\mathrm{Al}$ oxide $\left(\mathrm{Al}_{2} \mathrm{O}_{3}\right), \mathrm{Al}$ hydroxide $\left[\mathrm{Al}(\mathrm{OH})_{3}\right], \mathrm{Al}$ oxyhydroxide $(\mathrm{AlOOH})$ and $\mathrm{Zn}$ oxide $(\mathrm{ZnO}), \mathrm{Zn}$ hydroxide $\left[\mathrm{Zn}(\mathrm{OH})_{2}\right]$ formed both at the cut edge and under the paint. Since they were exposed to the marine environment, Simonkolleite $\left(\mathrm{Zn}_{5}(\mathrm{OH})_{8} \mathrm{Cl}_{2}\left(\mathrm{H}_{2} \mathrm{O}\right)\right)^{24,25)}$ may be present. Additionally, since a relatively large amount of carbon was detected (especially under the paint of $\mathrm{CF}-1$ ), $\mathrm{ZnCO}_{3}$ may also form. When the amounts of the $\mathrm{Al}$ oxides and the $\mathrm{Zn}$ oxides are compared on the steel surface of the cut edge [Point (A)], a larger amount of $\mathrm{Zn}$ oxides forms on $\mathrm{CR}$ and a larger amount of $\mathrm{Al}$ oxides forms on $\mathrm{CF}-1$. A larger amount of $\mathrm{Al}$ oxides formed under the paint on both $\mathrm{CR}$ and $\mathrm{CF}-1$. At the edge of $\mathrm{CR}$, more iron oxide was detected than at the edge of CF-1. A larger amount of $\mathrm{Al}$ on the sheets with the $\mathrm{MgV} /$ $\mathrm{ZnP}$ primer may correspond with better protection than the sheets with the $\mathrm{Cr}$ primer.

\subsection{Effect of Pigment on Edge Creep}

To elucidate the effect of pigment on the edge creep, the polarization curve and EIS of 55\% Al-Zn were measured in a $3 \% \mathrm{NaCl}$ solution suspended with various pigments. Figure 6 shows the polarization curves of $55 \% \mathrm{Al}-\mathrm{Zn}[(\mathrm{a})$ cathode and (b) anode]. The oxygen reduction reaction (ORR) on 55\% Al-Zn was significantly suppressed by all the pigments. When only $\mathrm{ZnP}$ was added, a rapid increase in current was observed from around $-1.2 \mathrm{~V}$. This current increase was attributed to the reduction of zinc oxide or zinc hydroxide $\left[\mathrm{ZnO}\right.$ or $\left.\mathrm{Zn}(\mathrm{OH})_{2}\right]$ film. ${ }^{26,27)}$ However, the current did not appear in the solution suspended with $(\mathrm{MgV} / \mathrm{ZnP})$. Note that electrochemically active zinc oxide does not form

Table 3. EDS point analysis of corrosion products on the steel surface at cut edge (Point (A) in Fig. 5) and under painted film (Point (B)).

\begin{tabular}{ccccccc}
\hline Analysis part & Sample name & $\mathrm{Al}$ & $\mathrm{Zn}$ & $\mathrm{Fe}$ & $\mathrm{C}$ & $\mathrm{O}$ \\
\hline \multirow{2}{*}{ Cut edge } & $\mathrm{CR}(\mathrm{Cr})$ & 11.7 & 27.8 & 12.9 & 12 & 29.9 \\
& $\mathrm{CF}-1(\mathrm{MgV} / \mathrm{ZnP})$ & 24.5 & 12.4 & 6 & 16.9 & 29 \\
\multirow{2}{*}{ Under the paint } & $\mathrm{CR}(\mathrm{Cr})$ & 28.7 & 12.4 & 1.3 & 11.9 & 37.9 \\
& $\mathrm{CF}-1(\mathrm{MgV} / \mathrm{ZnP})$ & 13.5 & 6.6 & 2.6 & 37 & 28.1 \\
\hline
\end{tabular}
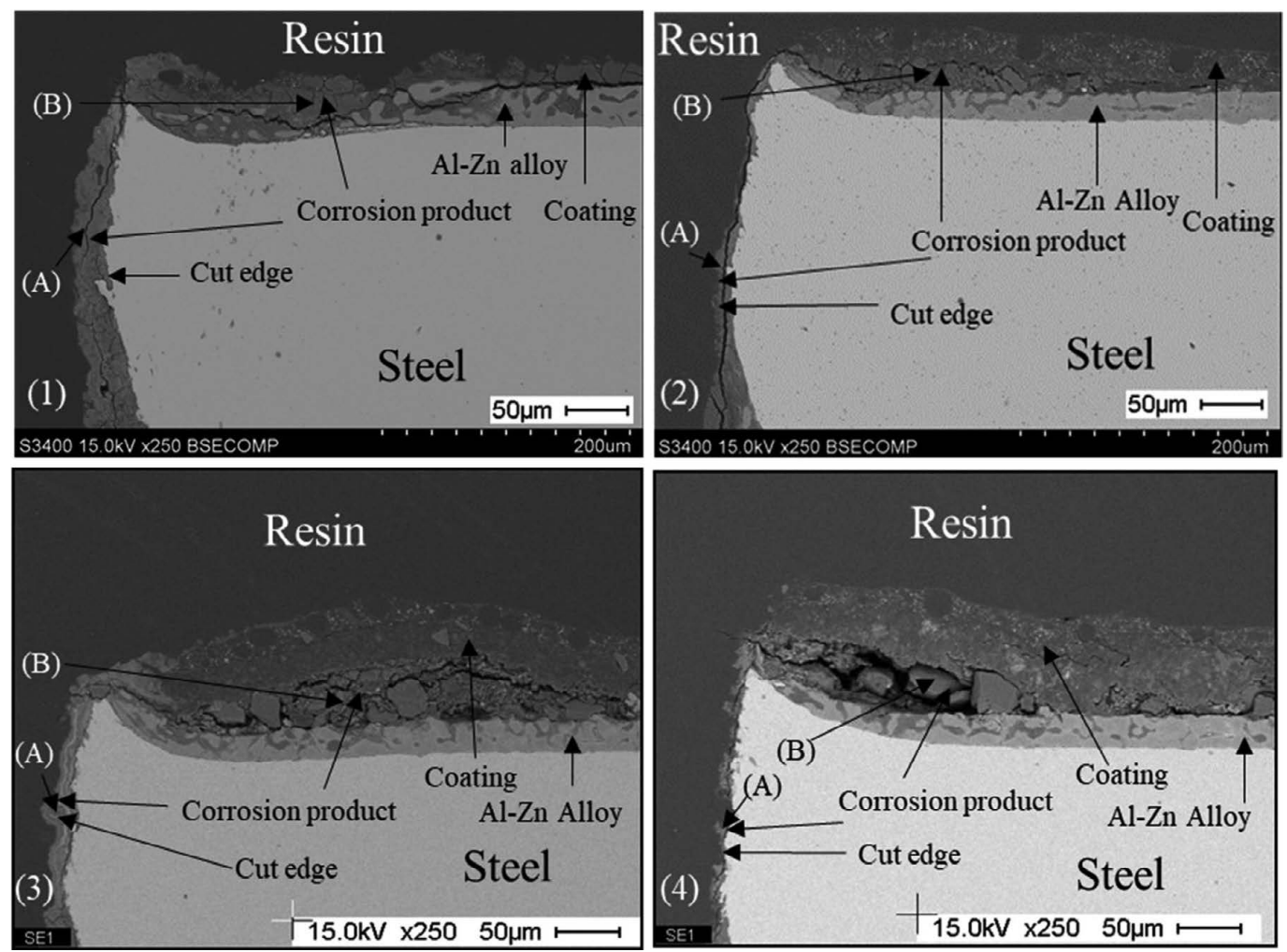

Fig. 5. SEM images of cross sections near the cut edge of upward burr side of (1) CR (Chromate), (2) CF-1 (MgV/ZnP), (3) CF-2 (Silicate), and (4) CF-3 (MgV) after two-years exposure test at Okinawa. 

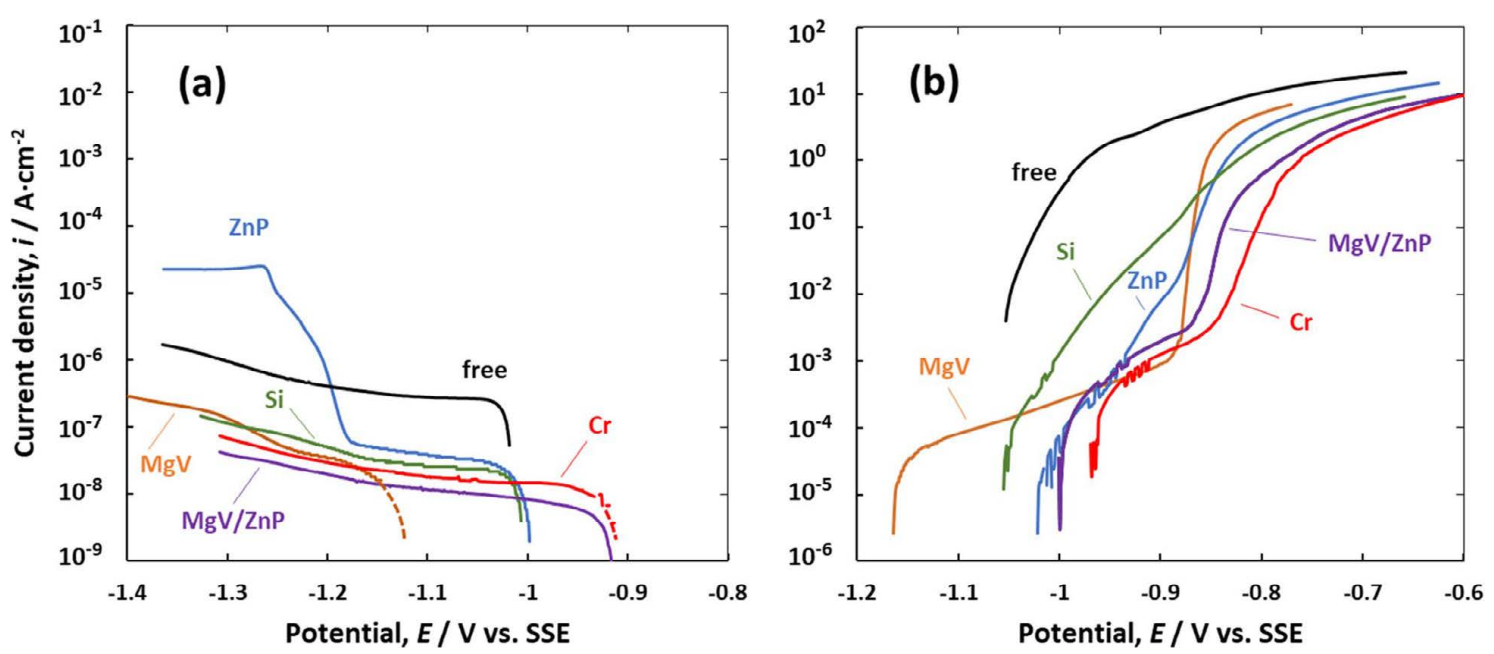

Fig. 6. Cathodic (a) and anodic (b) polarization curves of 55\%Al-Zn steel sheet measured at a potential scan rate of 1 $\mathrm{mV} \cdot \mathrm{s}^{-1}$ in $3 \% \mathrm{NaCl}$ solutions suspended with various pigments. (Online version in color.)

under the coexistence with $\mathrm{MgV}$.

When 55\% Al-Zn was anodically polarized from OCP, a passive potential region appeared, followed by a rapid increase in anodic current. The passive current was significantly suppressed by the addition of the pigments. This rapid increase in the anodic current was mainly due to the dissolution of zinc from the Zn-rich phase of the $\mathrm{Zn}-\mathrm{Al}$ coating. ${ }^{22)}$ The breakdown potential $\left(E_{\mathrm{b}}\right)$ at which the zinc dissolution starts shifted in the noble direction after the addition of the pigments. In other words, the pigments stabilized the passivation film. The $E_{\mathrm{b}}$ shifted to the higher potential in the order of free $<\mathrm{Si} \approx \mathrm{ZnP}<\mathrm{MgV} \approx \mathrm{MgV} / \mathrm{ZnP}<\mathrm{Cr}$. This anodic polarization behavior suggests that the $\mathrm{MgV}$ and $\mathrm{Cr}$ are highly effective in suppressing the dissolution of zinc from the $\mathrm{Zn}$-rich phase. Figure 7 shows the EIS of $55 \% \mathrm{Al}-\mathrm{Zn}$ steel sheet in a $3 \% \mathrm{NaCl}$ solution suspended with the various pigments. These are the EIS characteristics in OCP. In the absence of pigment, two time constants appear in the frequency range of $100 \mathrm{kHz}-10 \mathrm{mHz}$. The time constant appearing in the higher frequency may be related to the film resistance and capacitance of $\mathrm{Al}$ oxides and the time constant in the lower frequency may be due to the charge transfer resistance and electric double-layer capacitance. $^{22,28)}$ In the presence of the pigments, the two time constants were not clearly separated in the frequency domain. The reciprocal of impedance at the low frequency is generally used as an index of the corrosion rate. ${ }^{29-31)}$ The low-frequency impedance indicates that all the pigment significantly suppresses the corrosion rate of $55 \% \mathrm{Al}-\mathrm{Zn}$. The EIS measurements at OCP indicate that when $55 \% \mathrm{Al}-\mathrm{Zn}$ is not electrically coupled with $\mathrm{CS}$, the corrosion resistance of $55 \% \mathrm{Al}-\mathrm{Zn}$ is significantly improved by all pigments used in this experiment. Additionally, its anticorrosive effect does not depend on the pigments.

\subsection{Effect of Pigment on the Oxygen Reduction Reac- tion on the Carbon Steel Surface}

In the early stages of the corrosion of $55 \% \mathrm{Al}-\mathrm{Zn}$ steel sheet, the bare steel surface at the cut edge is directly exposed to the environment. Therefore, the effect of the pigments on the corrosion of CS was investigated. Figure 8 shows the polarization curves [(a) cathode and (b) anode] of

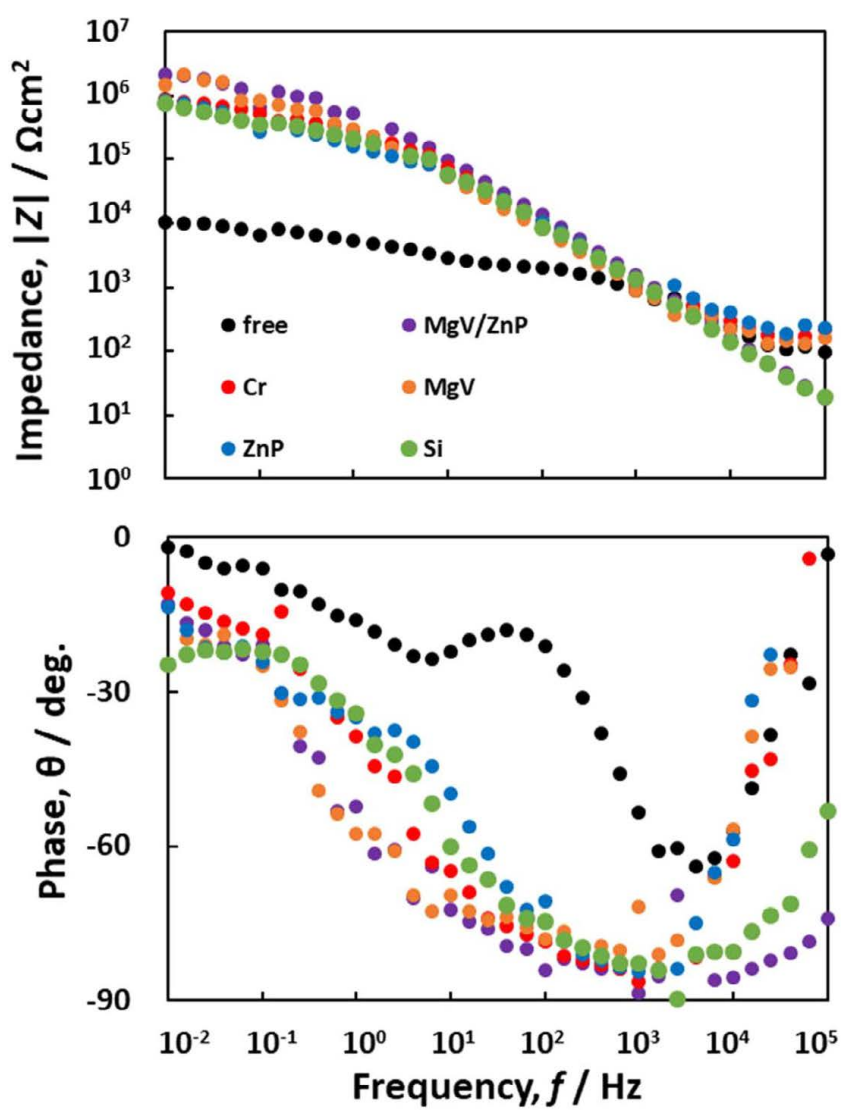

Fig. 7. EIS of $55 \% \mathrm{Al}-\mathrm{Zn}$ in $3 \% \mathrm{NaCl}$ solution suspended with various pigments. (Online version in color.)

$\mathrm{CS}$ in a $3 \% \mathrm{NaCl}$ solution suspended with $\mathrm{Cr}$ and $\mathrm{MgV} / \mathrm{ZnP}$. The cathode polarization curve clearly demonstrates (a) the effect of the pigment on the ORR was extremely small compared to that on $55 \% \mathrm{Al}-\mathrm{Zn}$. Cr slightly inhibited the ORR on the CS surface, whereas $\mathrm{MgV} / \mathrm{ZnP}$ did not reduce the ORR. On the other hand, the anodic polarization curves (b) indicate that iron dissolution was considerably suppressed by the $\mathrm{MgV} / \mathrm{ZnP}$, and slightly by the $\mathrm{Cr}$.

From the EIS for CS (Fig. 9), the corrosion rate of CS decreased with $\mathrm{Cr}$ and $\mathrm{MgV} / \mathrm{ZnP}$. Since the corrosion rate was reduced by almost an order of magnitude with both pigments, they may protect the CS at the cut edge when it 

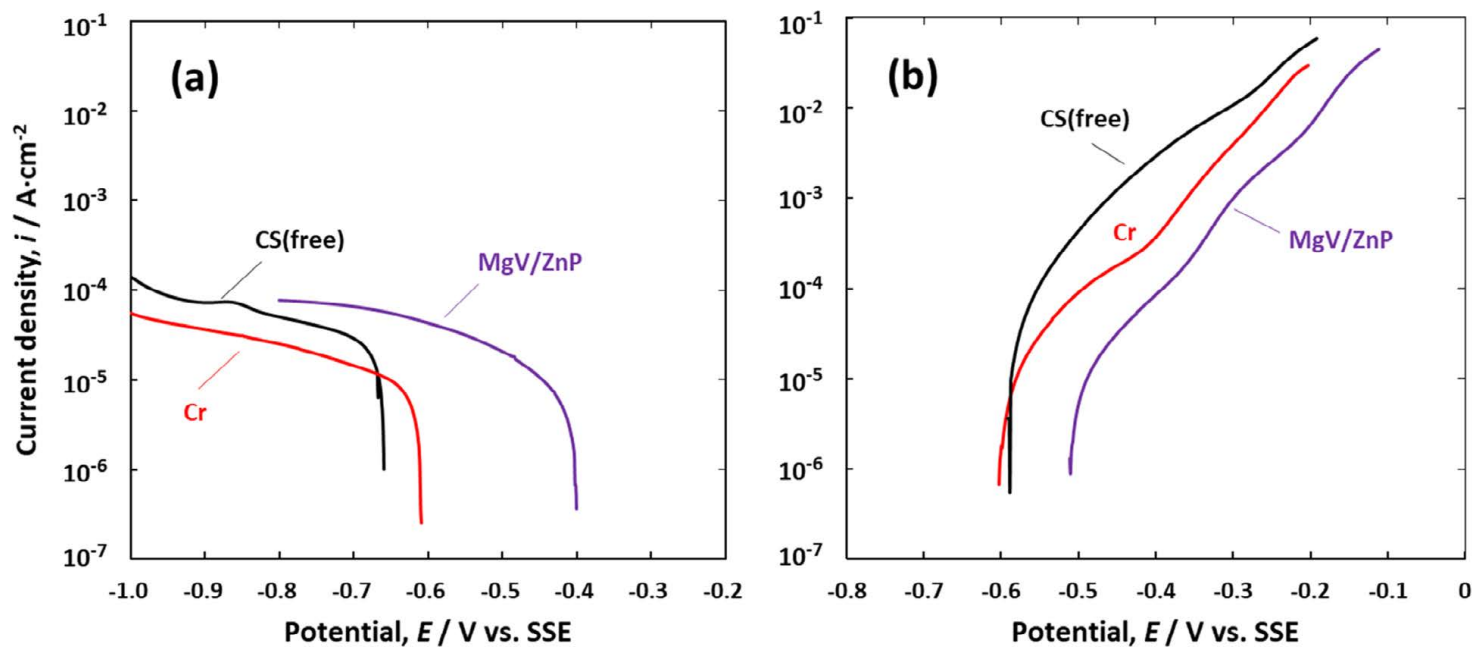

Fig. 8. Cathodic (a) and anodic (b) polarization curves of carbon steel measured at a potential scan rate of $1 \mathrm{mV} \cdot \mathrm{s}^{-1}$ in $3 \% \mathrm{NaCl}$ solutions suspended with various pigments. (Online version in color.)
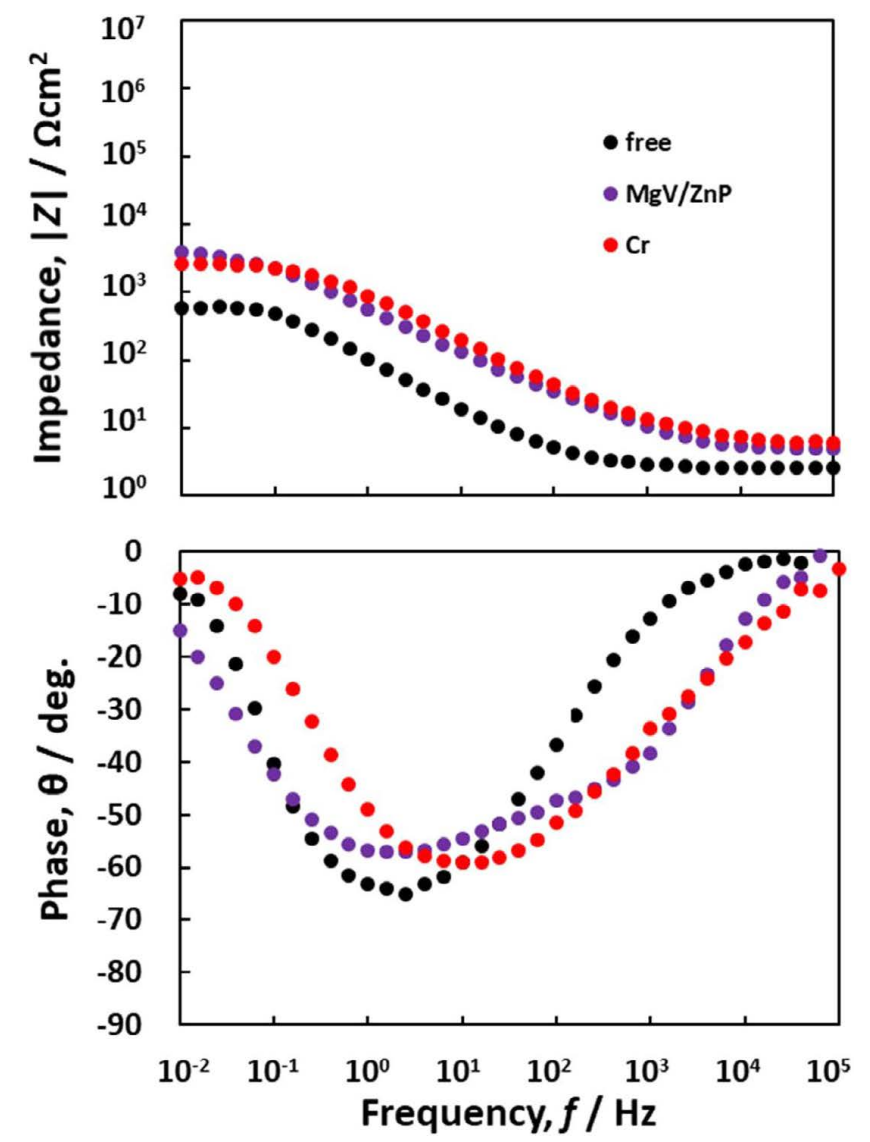

Fig. 9. EIS of carbon steel in $3 \% \mathrm{NaCl}$ solution suspended with various pigments. (Online version in color.)

is not electrically coupled with $55 \% \mathrm{Al}-\mathrm{Zn}$.

\section{Discussion}

When the $\mathrm{CS}$ at the cut edge and the 55\% $\mathrm{Al}-\mathrm{Zn}$ are electrically connected through a water film (when a galvanic couple is formed between them), the cathodic reaction (the ORR) and the anodic dissolution occur at different sites. Figures 10(a) and 10(b) respectively show the schematic drawings of the corrosion at the cut edge during the early stage and the later stage. (a) Zn-rich phase

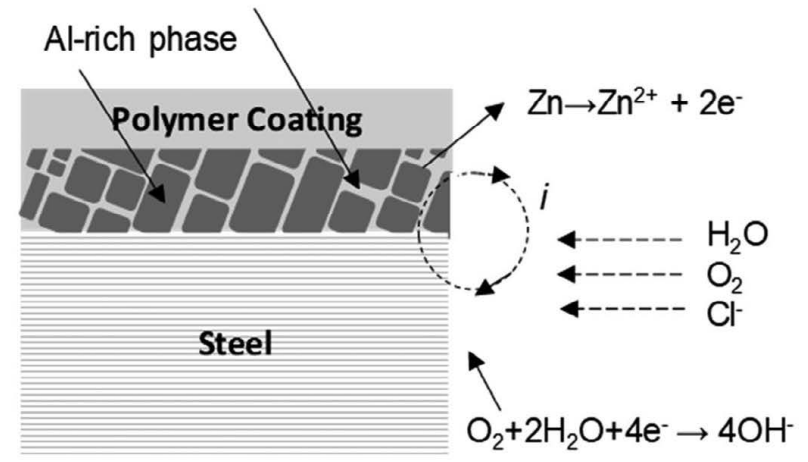

(b)

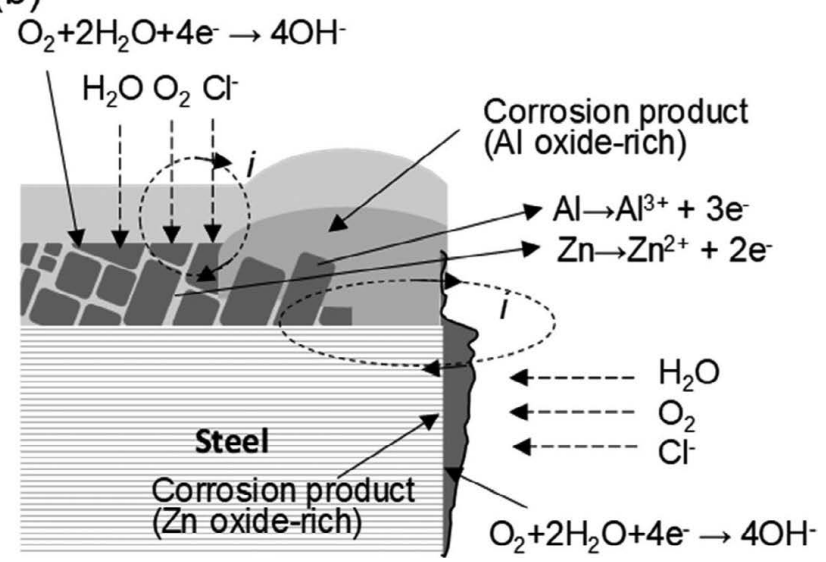

Fig. 10. Schematic drawings of pre-painted GL for describing cut edge corrosion at (a) early stage and (b) later stage.

During the early stage, the CS surface at the cut edge is not covered with the corrosion products. The bare surface of CS is directly exposed to the environment. Under the galvanic couple, the anodic dissolution occurs on the $55 \%$ $\mathrm{Al}-\mathrm{Zn}$ surface. The $55 \% \mathrm{Al}-\mathrm{Zn}$ consists of two phases; a Zn-rich phase and an Al-rich phase, and the zinc-rich phase selectively dissolves. ${ }^{22}$ ) The ORR takes place on the CS surface because it is very active to the ORR, as shown in Figs. 6(a) and 8(a). At this stage, the CS at the cut edge is 

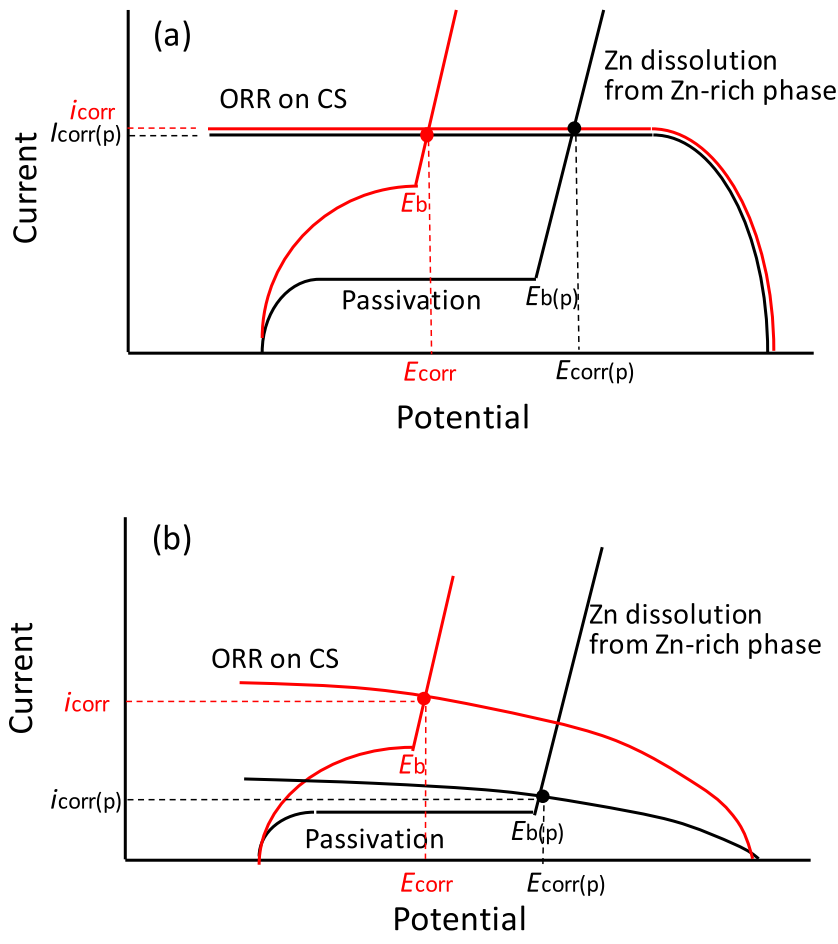

Fig. 11. Schematic drawing of internal anodic current of 55\%Al$\mathrm{Zn}$ and internal cathodic current of carbon steel in $\mathrm{NaCl}$ solution for describing cut edge corrosion of pre-painted $55 \% \mathrm{Al}-\mathrm{Zn}$ steel at early stage (a) and later stage (b). The red curves and black curves indicate the internal current in the absence and presence of primer, respectively. (Online version in color.)

galvanically protected by $55 \% \mathrm{Al}-\mathrm{Zn}$. Figure 11(a) shows a schematic diagram of the internal polarization curve at the early stage that describes the corrosion of $55 \% \mathrm{Al}-\mathrm{Zn}$ coupled with CS. As shown in Fig. 6(b), the surface of 55\% $\mathrm{Al}-\mathrm{Zn}$ is spontaneously passivated in a $3 \% \mathrm{NaCl}$ solution. When it is anodically polarized to the $E_{\mathrm{b}}$, the anodic current rapidly increases due to the onset of selective dissolution of zinc from the $\mathrm{Zn}$-rich phase because the passive film in the $\mathrm{Zn}$-rich phase should be less protective than that in the Al-rich phase. On the other hand, since the surface of CS is significantly active to the ORR, the cathodic polarization curve of CS shows the diffusion-controlled limiting current [Fig. 8(a)]. In Fig. 11(a), the internal polarization curves in the absence and presence of an anticorrosive pigment are indicated by the red and black lines, respectively. The potential at the intersection of the two is the corrosion potential $\left(E_{\text {corr }}\right)$ and the current at the intersection is the corrosion current $\left(i_{\text {corr }}\right)$ of $55 \% \mathrm{Al}-\mathrm{Zn}$. Since the $E_{\mathrm{b}}$ shifts to $E_{\mathrm{b}(\mathrm{p})}$ by the addition of an anticorrosive pigment in the noble direction [Fig. 6(b)], $E_{\text {corr }}$ of the couple of the $55 \% \mathrm{Al}-\mathrm{Zn}$ and the CS will shift to a more positive value $\left(E_{\text {corr(p) }}\right)$ in the presence of the pigment. However, since the inhibitory effect of the pigment to the ORR on the CS surface is very weak [Fig. $8(\mathrm{a})]$, the corrosion current $i_{\text {corr(p) }}$ of $55 \% \mathrm{Al}-\mathrm{Zn}$ with the pigment is not that different from that of the $i_{\text {corr }}$ without the pigment. At the early stage, the corrosion of $55 \% \mathrm{Al}-\mathrm{Zn}$ is expected to proceed from the cut edge at a relatively high rate, with or without anticorrosive pigment.

In Fig. 10(b), the edge corrosion during the later stage is schematically drawn. A large amount of Al-rich porous corrosion products (Table 3 ) accumulated on the $55 \% \mathrm{Al}-\mathrm{Zn}$ surface under the paint, and the CS surface at the cut edge is completely covered with a $\mathrm{Zn}$-rich corrosion product film (Fig. 5). The main reaction of the anodic reaction of corrosion is the selective dissolution of zinc from the $\mathrm{Zn}$-rich phase of 55\% $\mathrm{Al}-\mathrm{Zn}$. The dissolved zinc ions move through the porous corrosion product to the CS surface at the cut edge by migration and/or diffusion. A smaller amount of dissolved $\mathrm{Al}$ ions remains under the polymer coating as aluminum oxides, leading to the formation of the Al-rich corrosion products (Table 3 ). The cathodic reaction progresses on the cut edge of the CS surface, but the activity against the ORR is significantly reduced by the corrosion product deposition. Therefore, the ORR of the galvanic couple proceeds not only on the CS cut edge surface, but also on the 55\% Al-Zn surface. As a result, the CS at the cut edge is protected by both the barrier effect of the mixed $\mathrm{Al}-\mathrm{Zn}$ corrosion products (Zn-rich) and the galvanic coupling with $55 \% \mathrm{Al}-\mathrm{Zn}$. Figure 11(b) shows the internal polarization curve when the CS at the cut edge is fully covered with the corrosion products and describes the cut edge corrosion at the later stage. The ORR on the CS surface is significantly suppressed by the deposit of the Al-Zn corrosion products. In this case, the ORR is no longer diffusion-controlled, and the ORR current is dependent on potential, as shown by the red curve in Fig. 11(b). The anodic dissolution of $55 \% \mathrm{Al}-\mathrm{Zn}$ is also slightly suppressed by the deposit of the corrosion products. As a result, the corrosion current $\left(i_{\text {corr }}\right)$ of $55 \% \mathrm{Al}-\mathrm{Zn}$ is expected to be slightly smaller than the curve at the early stage. The black curve in Fig. 11(b) is the internal polarization curve in the presence of the anticorrosive pigment. Since the ORR on the $55 \% \mathrm{Al}-\mathrm{Zn}$ surface is strongly suppressed by the pigment (Fig. 6), the ORR on the CS surface covered with the $\mathrm{Al}-\mathrm{Zn}$ corrosion products is also suppressed by the pigment, unlike the bare CS surface. Additionally, the onset potential $\left(E_{\mathrm{b}}\right)$ of the zinc dissolution shifts significantly in the positive direction by the addition of pigment. Therefore, from Fig. 11(b), it is predicted that the corrosion rate $\left(i_{\mathrm{corr}(\mathrm{p})}\right)$ in the presence of the pigment will be considerably smaller than that of the pigment-free material $\left(i_{\text {corr }}\right)$. Thus, the progress of the cut edge corrosion is increasingly suppressed as $E_{\mathrm{b}}$ becomes higher. The $E_{\mathrm{b}}$ values of $\mathrm{MgV}, \mathrm{MgV} / \mathrm{ZnP}$, and $\mathrm{Cr}$ are clearly higher than those of $\mathrm{ZnP}$ and $\mathrm{Si}$ [Fig. 6(b)]. In the evaluation of the edge creep by the 24-month exposure test (Fig. 4), MgV/ $\mathrm{ZnP}$ and $\mathrm{Cr}$ showed excellent edge creep resistances, and $\mathrm{Si}$ showed a poor resistance. The $E_{\mathrm{b}}$ obtained from the anodic polarization curve demonstrated a good correlation with the evaluation results of edge creep. Therefore, the difference in the anticorrosion effect of the pigments in the primer of 55\% $\mathrm{Al}-\mathrm{Zn}$ is due to the difference in the ability to suppress the selective dissolution of zinc from the Zn-rich phase. Additionally, the inhibitory effect of the Al-Zn oxide film that forms on the CS surface on the ORR plays an important role in reducing the galvanic current. From the analysis of the oxide films (Fig. 5), those with a different composition ratio of $\mathrm{Al}$ and $\mathrm{Zn}$ were formed on $\mathrm{CS}$ in $\mathrm{MgV} / \mathrm{ZnP}$ and $\mathrm{Cr}$. In the future, it is necessary to investigate the ORR inhibitory ability of the Al-Zn corrosion product film formed on CS by electrically coupling it with $55 \% \mathrm{Al}-\mathrm{Zn}$. 


\section{Conclusions}

The prepainted 55\% Al-Zn steel sheets with four different anticorrosive pigments $(\mathrm{Cr}, \mathrm{MgV} / \mathrm{ZnP}, \mathrm{Si}$, and $\mathrm{MgV})$ in the primer were exposed at five locations (AZ, TYO, FL, $\mathrm{KAG}$, and $\mathrm{OK}$ ) for 24 months to evaluate the anticorrosion property of the pigments. Electrochemical tests of the $55 \% \mathrm{Al}-\mathrm{Zn}$ steel and the CS were performed in 3\% $\mathrm{NaCl}$ solution suspended with the pigments to describe the edge creep resistance of the pigments. The following conclusions were drawn.

(1) The cut edge creep did not progress in any of the pigments in AZ (dry desert), but red rust was observed on the CS at the cut edge. At all the other exposure sites, the cut edge creep property of $\mathrm{Si}$ was the worst, and $\mathrm{MgV} / \mathrm{ZnP}$ was comparable to that of $\mathrm{Cr}$.

(2) EDS analysis indicated Al-rich corrosion product was deposited on the $55 \% \mathrm{Al}-\mathrm{Zn}$ surface under the paint. EDS analysis also indicated that $\mathrm{Zn}$-rich $\mathrm{Al}-\mathrm{Zn}$ mixed oxide films formed on the CS surface at the cut edge. The mixed oxide film for $\mathrm{MgV} / \mathrm{ZnP}$ contained a higher content of $\mathrm{Al}$ than the other pigments.

(3) The effect of the pigment on the creep property at the cut edge was successfully explained by the anodic polarization curve of 55\% Al-Zn steel and the cathodic polarization curve of CS. The anticorrosive pigment strongly suppressed the zinc dissolution during the Zn-rich phase. The Al-Zn oxide film that formed on the CS surface at the cut edge may also play an essential role in the progress of the edge creep.

\section{Acknowledgment}

The authors acknowledge SUGA Weathering Technology Foundation for providing the outdoor exposure test sites and meteorological data.

\section{REFERENCES}

1) D. J. Blickwede: Tetsu-to-Hagané, 66 (1980), 821 (in Japanese).

2) T. Ooi: J. Surf. Finish. Soc. Jpn., 62 (2011), 8 (in Japanese).

3) M. Sagiyama: J. Surf. Finish. Soc. Jpn., 54 (2003), 316 (in Japanese).

4) H. Furukawa and H. Kanai: J. Jpn. Coat. Technol. Assoc., 48 (2013), 543 (in Japanese).

5) M. Ehara: J. Jpn. Inst. Light Met., 50 (2000), 584 (in Japanese).

6) T. Aoe: J. Surf. Finish. Soc. Jpn., 49 (1998), 221 (in Japanese).

7) O. Gharbi, S. Thomas, C. Smith and N. Birbilis: npj Mater. Degrad., 2 (2018), 12

8) JIS G 3322: 2019, Prepainted hot-dip 55\% aluminium-zinc alloycoated steel sheet and strip (in Japanese)

9) T. Tsujita, N. Nishida, Y. Takeuchi and K. Ohsawa: J. Jpn. Coat. Technol. Assoc., 49 (2014), 232 (in Japanese).

10) T. Prosek, A. Nazarov, A. Le Gac and D. Thierry: Prog. Org. Coat., 83 (2015), 26

11) K. Ueda, A. Takahashi and Y. Kubo: Proc. 8th Int. Conf. on Zinc and Zinc Alloy Coated Steel Sheet (Galvatech 2011), (Genova), AIM, Milano, (2012), 13.

12) T. Shinohara: J. Surf. Finish. Soc. Jpn., 62 (2011), 25 (in Japanese).

13) Y. Sugawara, K. Araake, I. Muto, M. Takahashi, M. Matsumoto and N. Hara: ISIJ Int., 56 (2016), 2267. https://doi.org/10.2355/ isijinternational.ISIJINT-2016-336

14) H. E. Townsend: Corrosion, 54 (1998), 561. https://doi.org/10.5006/ 1.3284884

15) H. Nomura: J. Surf. Finish. Soc. Jpn., 70 (2019), 588 (in Japanese).

16) JIS Z 2371: 2015, Methods of salt spray testing (in Japanese).

17) JASO M609-91: 1991, Corrosion test method for automotive materials (in Japanese)

18) H. Kajiyama, S. Fujita, K. Fujii and M. Sakai: Zairyo-to-Kankyo, 55 (2006), 356 (in Japanese).

19) H. Matsuda, A. Sakamoto, M. Hayashi and Y. Miyoshi: Zairyo-toKankyo, 61 (2012), 64 (in Japanese).

20) Y. Sato: Corros. Eng. (Jpn.), 32 (1983), 166 (in Japanese).

21) I. Sekine, Y. Toshima and M. Yuasa: J. Jpn. Soc. Colour Mater., 66 (1993), 724 (in Japanese).

22) A. Nishikata, T. Tsuda and T. Tsuru: Tetsu-to-Hagané, 95 (2009), 565 (in Japanese).

23) F. Deflorian, L. Fedrizzi and S. Rossi: Corrosion, 54 (1998), 598. https://doi.org/10.5006/1.3287635

24) W. Feitknecht: Chem. Ind., 36 (1959), 1102.

25) T. E. Graedel: J. Electrochem. Soc., 136 (1989), 193C.

26) A. P. Yadav, A. Nishikata and T. Tsuru: J. Electroanal. Chem., 585 (2005), 142.

27) C. Deslouis, M. Duprat and C. Tulet-Tournillon: J. Electroanal. Chem. Interfacial Electrochem., 181 (1984), 119.

28) H. Katayama, Y. Tay, A. S. Viloria, A. Nishikata and T. Tsuru: Mater. Trans., JIM, 38 (1997), 1089.

29) M. Stern and A. L. Geary: J. Electrochem. Soc., 104 (1957), 56.

30) M. Maeda, X. Y. Li, A. Ooi, E. Tada and A. Nishikata: ISIJ Int., 60 (2020), 337.

31) A. P. Yadav, A. Nishikata and T. Tsuru: ISIJ Int., 44 (2004), 1727. 